\title{
O currículo de Ciências e o interesse dos estudantes brasileiros: uma aproximação necessária ${ }^{1}$
}

Ana Maria Santos Gouw*

Helenadja Santos Mota**

Nelio Bizzo***

*Professora Adjunta do Departamento de Ciências Exatas e da Terra Universidade Federal de São Paulo - Campus Diadema

E-mail: anagouw@gmail.com

**Pesquisadora da Faculdade de Educação da Universidade de São Paulo, área Educação, ênfase em Ensino de Ciências

E-mail: helenrios@gmail.com ***Professor Titular do Departamento de Metodologia do Ensino da Faculdade de Educação da Universidade de São Paulo

E-mail:nelio.bizzo@gmail.com
Resumo: 0 desencanto dos estudantes pela carreira científica tem provocado um movimento em prol de se ouvir o que os alunos têm a dizer das aulas de Ciências e dos temas científicos de maior interesse. Um desses movimentos é o projeto "The Relevance of Science Education" (Rose), implementado em mais de 40 países e objeto de estudo do trabalho aqui descrito. A pesquisa encontra-se dentro do campo da avaliação educacional. A amostra, de representatividade nacional, envolveu 2.365 estudantes, oriundos de 84 escolas. Os dados obtidos revelam que o brasileiro possui grande interesse pelos temas científicos abordados na escola, sendo os temas de maior interesse aqueles relacionados à Biologia Humana. Especificamente sobre a evolução biológica, tema bastante controverso no currículo de Biologia, observamos que os jovens estudantes brasileiros estão abertos a discussões sobre o tema.

Palavras-chave: Currículo de Ciências. Interesse dos estudantes. Avaliação educacional.

Agradecemos ao CNPq pelo financiamento concedido para a realização desta pesquisa, através do edital Universal 2009/14 e a CAPES pela concessão das bolsas de doutorado. 
INTRODUÇÃO

Tem-se observado em diversos países ao redor do globo um desinteresse geral dos jovens em relação à ciência escolar, o que tem desencadeado o baixo ingresso, por parte dos estudantes, nas carreiras científicas (AIKENHEAD, 2004; BARAM-TSABARI et al., 2009; EUROPEAN COMMISSION, 2004, EUROPEAN COMMISSION, 2007; FENSHAM, 2004; JENKINS, 2006; JENKINS; NELSON, 2005; OSBORNE; SIMON; COLLINS, 2003; OSBORNE, 2006; OSBORNE; DILLON, 2008; SHAMOS; HOWES, 1996; TOMEI, 2008; SCHREINER; SJØBERG, 2004; VÁZQUEZ; MANASSERO, 2008).

Anthony Tomei (2008) comenta, sobre esse aspecto, que há deficiências observadas na pedagogia, no currículo e nas avaliações, mas o problema mais profundo reside no fato de a ciência escolar nunca ter fornecido uma educação satisfatória para a maioria, o que tem gerado implicações adversas para a formação de futuros cientistas.

Se há problemas na educação científica, como a baixa proficiência observada entre os jovens brasileiros, e o pouco interesse, o que os próprios estudantes têm a dizer sobre isso? Esta pesquisa ouviu 2.365 jovens oriundos de todos os estados brasileiros, com o intuito que conhecer suas preferências e seus temas científicos de maior interesse que estão presentes no currículo escolar brasileiro.

Para isso, foi implementado o projeto internacional “The Relevance of Science Education” (Rose), elaborado por pesquisadores da Universidade de Oslo, que visa averiguar a relevância do conhecimento científico e tecnológico para os jovens que estão finalizando os estudos compulsórios (cerca de 15 anos de idade). 0 projeto tem sido adaptado de forma colaborativa por diversos pesquisadores ao redor do mundo e seu instrumento de coleta de dados - um questionário fechado com 245 itens - já foi aplicado em mais de 40 países (SCHREINER; SJØBERG, 2004).

Os pesquisadores envolvidos no projeto ROSE concordam com o fato de que o currículo de Ciências deve contemplar as necessidades dos estudantes, considerar o que eles consideram relevante, de forma que a voz e a visão do aluno devam influenciar os elaboradores de currículos e sua implementação nas escolas (ANDERSON, 2006; CAVAS et al., 2009; JENKINS, 2006; JIDESJÖ; OSCARSSON; KARLSSON, 2009; MATTHEWS, 2007; SCHREINER; SJØBERG, 2004; VÁZQUEZ ALONSO; MANASSERO MAS, 2008). 
Uma solução para enfrentar o baixo interesse dos jovens diante do ensino de Ciências é apontada por Deboer (2000): a necessidade de se decidir o que ensinar e como ensinar com base no interesse dos alunos, na experiência dos professores e nos contextos locais. O objetivo do ensino não deve ser propiciar aos alunos notas altas em testes internacionais, mas sim formar alunos que consideram a ciência interessante e importante, com aplicação direta em suas próprias vidas e aptos a participar das conversas sobre ciência que ocorrem na sociedade.

Chassot (2006, p. 96) corrobora esta visão ao afirmar que não ensinamos ciências para formar cientistas, mas para ensinar "uma linguagem que facilite o entendimento do mundo pelos alunos e alunas".

Fourez (2003, p. 110) aponta que a crise no ensino de Ciências, refletida no baixo ingresso dos alunos nas carreiras científicas, deve-se em grande parte a uma ciência escolar que não promove o interesse dos alunos:

Os alunos teriam a impressão de que se quer obrigá-los a ver o mundo com os olhos de cientistas. Enquanto o que teria sentido para eles seria um ensino de ciências que ajudasse a compreender o mundo deles. [...] Ou seja, os jovens prefeririam cursos de ciências que não sejam centrados sobre os interesses de outros (quer seja a comunidade de cientistas ou o mundo industrial), mas sobre os deles próprios.

O problema envolvendo o baixo ingresso dos jovens nas carreiras científicas foi apresentado em detalhes no relatório "Europe Needs More Scientists" (EUROPEAN COMMISSION, 2004). No documento se destaca a preocupação com o fato de que dentre os 25 países membros da União Europeia, apenas na Grécia e na Bélgica (parte flamenca) não se observa uma diminuição no número de jovens que escolhem estudar Ciências nas escolas.

Um dos tópicos abordados pelo relatório no enfrentamento desse problema é a ciência escolar. Segundo o documento, é apenas na escola que os jovens são expostos à ciência de forma sistemática, organizada e explícita. E muito provavelmente os primeiros encontros com o pensamento científico trarão impressões duradouras em sua percepção sobre a natureza da ciência e sobre suas atitudes em relação a ela. 0 relatório ainda comenta que o ensino e aprendizagem da ciência na escola deveria proporcionar o aumento do interesse dos jovens pela ciência e estudos correlatos, incluindo carreiras e empregos futuros (EUROPEAN COMMISSION, 2004).

Outro relatório, organizado pela Organização para a Cooperação e Desenvolvimento Econômico (OECD, na sigla em inglês), denominado 
“Evolution of Student Interest in Science and Technology Studies" (OECD, 2006), apresentou que nos países da OECD, nos últimos 15 anos, houve aumento do número de alunos no ensino superior, porém a proporção de alunos que se matricularam nas áreas de ciência e tecnologia caiu acentuadamente, em especial nas áreas de Ciências Físicas e Matemática.

No âmbito latino-americano, essa situação também tem sido observada, o que fez com que o Observatório Iberoamericano de Ciência, Tecnologia e Sociedade, vinculado à Organização dos Estados Iberoamericanos (OEI), delineasse como uma das Metas Educativas 2021 a necessidade de estimular os jovens estudantes às carreiras científicas e tecnológicas, especificando que até o ano de 2015 haja um aumento de 10\% da proporção de jovens que optam por tais carreiras (OEI, 2010; POLINO; CHIAPPE, 2011).

Osborne et al. (2003) relatam haver uma diminuição do interesse pela ciência com o passar dos anos escolares, principalmente a partir do ensino médio. As crianças nas séries iniciais apresentam maior interesse pela ciência que os jovens que finalizam a educação básica. Tal fato também é evidenciado em Israel (TRUMPER, 2006), onde se tem observado que o interesse pela ciência, principalmente pela física, tem diminuído durante a escolaridade.

Baram-Tsabari et al. (2009) comentam que as decisões dos jovens sobre os rumos de sua formação acadêmica são influenciadas em alto grau pelo interesse por temas desenvolvidos nos anos anteriores. E comentam que a habilidade em aprender também afeta a escolha da futura carreira.

Entretanto, há um consenso voltado ao fato de que todo ensino deve ser construído com base nos interesses e experiências da criança. Para que os conteúdos de ensino sejam significativos para o aluno, é necessário que tenham algum tipo de relevância, e que se encaixem no contexto pessoal e social do estudante (SJØBERG, 2000).

Jenkins (2006) aponta, como hipótese ainda não testada, que quanto mais se sabe sobre os interesses, entusiasmos, crenças e atitudes dos estudantes, mais exequível será desenvolver um currículo escolar na área das Ciências que engaje os estudantes e os ajude a diminuir as diferenças existentes no que se refere às suas escolhas acadêmicas.

Assim, no que se refere à educação científica, a necessidade de se ouvir o estudante se torna imperativa quando deparamos com o fato de os jovens estarem cada vez menos interessados na ciência escolar formal. BaramTsabari e Yarden (2005) apontam para a importância de se ouvir a voz do 
aluno na construção do currículo ou nas reformas dos cursos de Ciências, de maneira que se tornem mais interessantes e atrativos para os alunos.

Dessa forma, este artigo traz dados oriundos da aplicação do Projeto Rose no Brasil que procuraram contemplar as seguintes questões: a) quais são os temas da ciência escolar que mais e menos interessam os jovens brasileiros e b) quais são as percepções dos jovens brasileiros em relação à evolução biológica, um dos temas mais controversos do currículo da Biologia?

\section{Metodologia de PESQUisa}

A pesquisa aqui descrita está situada dentro do campo da avaliação educacional. A avaliação educacional não se restringe à aplicação de testes e provas, visando a averiguação da proficiência do aluno em determinado assunto. Segundo Vianna (1992, p. 100), a avaliação centrada no aluno pode estar focada tanto nos aspectos cognitivos (formativo e somativo) quanto nos não cognitivos, como as "atitudes, interesses e aptidões".

Buriasco (2000, p. 156) destaca a diversidade de objetivos da avaliação educacional atual, tais como "subsidiar o processo de ensino e aprendizagem, fornecer informações sobre os alunos, professores e escolas, atuar como respaldo da certificação e da seleção e orientar na elaboração de políticas educacionais".

Metodologias de avaliação educacional em âmbito nacional implicam abordagens de natureza quantitativa. Sobre elas, é interessante ressaltar a escassa literatura existente no País. Gatti (2004, p. 13) declara que

Há mais de duas décadas que na formação de educadores e de mestres e doutores em educação não se contemplam estudos disciplinares sobre esses métodos. No entanto, há problemas educacionais que para sua contextualização e compreensão necessitam ser qualificados através de dados quantitativos.

A autora considera que estudos quantitativos contextualizados por perspectivas teóricas trazem subsídios para que os fenômenos educacionais sejam tratados além dos casuísmos e "achômetros" construídos a partir do senso comum, trazendo elementos concretos para o enfrentamento de políticas, planejamento e orientação de ações pedagógicas (GATTI, 2004, p. 26). 
A avaliação educacional descrita nesta pesquisa teve como objeto o interesse dos alunos frente à ciência escolar através da aplicação do instrumento Rose, um questionário com questões fechadas que utiliza afirmações acerca da ciência, no qual o aluno é convidado a assinalar seu grau de interesse em uma escala tipo Likert.

Tal instrumento, desenvolvido pelos organizadores do projeto na Noruega (SCHREINER; SJØBERG, 2004), foi adequado ao contexto brasileiro por Tolentino Neto (2008). 0 questionário Rose convida o aluno a assinalar qual é o seu nível de interesse sobre diversos temas da ciência, suas aulas de Ciências, sua posição em relação aos desafios ambientais, suas opiniões sobre ciência e tecnologia, suas experiências fora da escola e seu futuro emprego por meio de uma lista de 245 itens disposta em oito seções nomeadas por letras ( $A$ a H). No Brasil, foram incluídas 23 questões específicas sobre a religiosidade e a aceitação da evolução biológica, distribuídas em cinco seções (seções I a N).

As seções que trazem informações sobre o interesse pelos temas da ciência escolar, que estão descritas neste artigo, compreendem 108 itens distribuídos em três seções ( $A, C$ e E) do questionário Rose. Os itens consistem em afirmações curtas e simples sobre diversos assuntos e temas, tal como observado na Figura 1. (Ver Anexo 1.)

\section{A. $O$ que eu quero aprender}

Qualé o seu nível de interesse em aprender os seguintes assuntos ou temas?

(Assinale sua resposta preenchendo o quadradinho correspondente em cada linha. Se não entender, deixe a linha em branco).

\begin{tabular}{|c|c|c|c|c|c|}
\hline & & 1 & 2 & 3 & 4 \\
\hline 1 & Estrelas, planetas e o Universo & $\square$ & $\square$ & $\square$ & $\square$ \\
\hline 2 & Substâncias químicas, suas propriedades e como reagem & $\square$ & $\square$ & $\square$ & $\square$ \\
\hline 3 & O interior da Terra & $\square$ & $\square$ & $\square$ & $\square$ \\
\hline
\end{tabular}

Figura 1 - Recorte da Seção A do questionário Rose aplicado no Brasil.

O objetivo das seções $A, C$, e E do questionário é conhecer os assuntos que possuem o potencial de engajar e envolver os estudantes nas aulas de Ciências, não só através do aumento do entusiasmo, mas também do pensamento criativo e do crescimento individual. Conhecer por quais assuntos os jovens mais se interessam possibilita a construção de currículos mais significativos para os alunos (SCHREINER; SJØBERG, 2004). 
A escala Likert utilizada possui quatro opções - de desinteressado a muito interessado - sem opção neutra. A opção por uma escala com quatro pontos, e não com cinco, como são as escalas de Likert clássicas, está relacionada ao fato de que a opção neutra geralmente traz erros de interpretação: pode indicar um ponto central entre extremos, mas também falta de conhecimento ou entendimento da questão, indiferença ou mesmo falta de motivação. Assim, no caso do questionário Rose, o aluno é orientado a não responder quando não compreende a questão ou quando não quer responder à questão (SCHREINER; SJØBERG, 2004).

0 instrumento de coleta de dados foi impresso em cadernos com folhas ópticas, em que as respostas são preparadas para a leitura por meio de Intelligent Character Recognition (ICR), que proporciona a captura automática de dados. Cada caderno de respostas foi personalizado com um códigos de barras, o que permitiu sua fácil localização, tendo em vista a natureza anônima do instrumento.

A utilização desse sistema foi uma inovação brasileira para a pesquisa Rose, e contribui no que se refere à agilidade da tabulação dos dados, uma vez que é realizado por leitor automático, e à diminuição dos erros oriundos da tabulação manual.

\section{População-alvo}

A população-alvo desta pesquisa são os estudantes que estão completando os estudos compulsórios e iniciando a última etapa da educação básica, quando deverão tomar decisões sobre seu futuro profissional. Convencionouse que todos os países participantes do projeto Rose elegeriam a série escolar na qual se esperaria encontrar idealmente os estudantes de 15 anos. No caso brasileiro, esta norma foi traduzida optando pela aplicação a jovens do primeiro ano do ensino médio.

Para definir uma amostra de representatividade nacional foi utilizada como referência a amostra brasileira do Programa Internacional de Avaliação de Alunos (Pisa) realizado no ano de 2009, de forma que foram mantidas as mesmas características e representatividade da amostra original. Assim, o universo amostral deste estudo corresponde à amostra Pisa do ano de 2009.

A opção por ter como referência a amostra Pisa 2009 se deu pelo fato de ela ser estatisticamente significativa da população estudantil brasileira. Além disso, há proximidade entre o público-alvo da pesquisa Rose e do Pisa, e as 
informações das escolas participantes do Pisa 2009 podem ser acessadas por meio do Instituto Nacional de Estudos e Pesquisas Educacionais Anísio Teixeira (Inep).

Devido ao presente estudo ser realizado em escolas, houve a necessidade de aplicar o questionário junto a turmas de alunos, e não a alunos individualmente. Dessa forma, foi selecionada uma turma de $1^{\underline{0}}$ ano de ensino médio em cada unidade escolar participante, com tamanho médio estimado de 30 alunos, sendo o critério de escolha a presença de alunos de 15 anos de idade em sua maioria.

\section{Tamanho amostral}

Considerando o universo amostral acima descrito, foi desenhado um plano amostral inicial envolvendo o sorteio de 160 unidades escolares distribuídas em todos os estados brasileiros. Todos os alunos das escolas sorteadas (média de 30 por escola) deveriam ser incluídos na amostra. Considerando uma perda de $20 \%$ das escolas sorteadas e de $10 \%$ de alunos dentro das escolas, deveriam ser pesquisadas 128 escolas e 27 alunos em cada escola, resultando em 3.456 questionários preenchidos.

As estimativas de proporções calculadas para este tamanho amostral correspondem à obtenção de estimativas com erro de amostragem entre 3 e 4 pontos percentuais (sendo o ponto 3 o equivalente a 2.160 questionários e 0 ponto 4 o equivalente a 3.841 questionários), o que é considerado satisfatório para uma pesquisa realizada em âmbito nacional.

O período de coleta de dados ocorreu entre julho de 2010 e setembro de 2011. Os questionários foram enviados para as escolas por correio, juntamente com o Termo de Consentimento Livre e Esclarecido indicado pelo Comitê de Ética de instituição de pesquisa responsável pelo Projeto Rose no Brasil, bem como de envelopes selados para o retorno dos questionários preenchidos.

Ao final do período de coleta obtiveram-se 2.365 questionários preenchidos oriundos de 84 escolas situadas em todos os estados brasileiros, número que se manteve dentro da faixa correspondente à estimativa de erro de amostragem situado entre 3 e 4 pontos percentuais previstos inicialmente. 


\section{Descrição da amostra obtida}

Dentre as escolas participantes da pesquisa, 96\% estão localizadas em áreas urbanas e 4\% em áreas rurais. Em relação à dependência administrativa, 88\% são públicas estaduais, $4 \%$ são públicas federais e $8 \%$ privadas.

Dentre os jovens participantes (respostas válidas), 57,6\% são meninas e $42,3 \%$ são meninos, com idade média de 15,39 anos de idade.

Para o conhecimento de informações socioeconômicas, o questionário possuía duas questões: uma relacionada à posse de livros e outra relacionada ao número de banheiros presentes na casa do estudante. Observou-se que, no âmbito brasileiro, $71 \%$ dos alunos possuem menos de 50 livros em casa, 0 que indica acesso restrito a um bem cultural relativamente comum e de ampla distribuição, como é o caso dos livros didáticos. A faixa onde se concentrou maior porcentagem (37\%) foi a de 11 a 50 livros. Em relação ao número de banheiros, houve maior ocorrência de um banheiro nos domicílios dos alunos de todas as regiões brasileiras.

\section{RESULTADOS E DISCUSSÃO}

O que os jovens brasileiros mais (e menos) se interessam em aprender?

Os dados apresentados aqui correspondem àqueles obtidos junto às seções A, C e E do questionário Rose aplicado no Brasil, que questionavam ao aluno: "Qual é o seu nível de interesse em aprender os seguintes assuntos ou temas?”. Conforme declaram Schreiner e Sjøberg (2004), conhecer quais tópicos da ciência os jovens têm interesse em aprender poderá subsidiar questões envolvendo o currículo de Ciências atual, de forma a permitir o maior engajamento do estudante. Kwiek et al. (2007) afirmam que abordar na escola temas que despertem o interesse dos alunos pode ajudar a aumentar sua motivação e seu aprendizado.

Conforme explicitado anteriormente, as seções A, C e E do questionário contemplavam 108 questões envolvendo as mais diversas áreas da ciência. Para tornar mais palatáveis os resultados obtidos ao longo dessas questões, optou-se por apresentar os dados da seguinte forma: 1) pela exposição dos 20 itens com maior/menor pontuação entre meninos e meninas e 2) pela exposição das disciplinas/assuntos da ciência que mais/menos interessam meninos e meninas. 
Para a verificação de diferenças entre gênero foram utilizados testes de MannWhitney quando não se observou normalidade dos dados e o teste T Student quando foi detectada normalidade dos dados. Diferenças com valores de p<0,05 foram consideradas significativas.

Um panorama geral do interesse do jovem brasileiro pela ciência na escola pode ser observado pela análise das 20 respostas com maior e menor pontuação, discriminando meninos e meninas (sendo a escala Likert utilizada com 4 pontos). As questões estão apresentadas precedidas de um código, sendo a letra referente à seção e o número referente à sequência da questão dentro da seção. Os resultados podem ser observados nas tabelas 1 e 2 .

Tabela 1 - Itens das seções A, C e E do questionário Rose com maior pontuação entre os jovens brasileiros.

\section{Meninos}

A09 - Sexo e reprodução

C07 - Como os computadores 3,17 funcionam

E10-Como prestar primeiros socorros 3,17

A40 - Como manter o meu corpo forte 3,15 e em boa condição física

A30 - Como funciona a bomba 3,07 ${ }_{\text {E09 }}^{\text {atômica }}$ - As doenças sexualmente 3,06 transmissiveis e como se proteger delas

C08 - A possibilidade de vida fora do 3,03 planeta Terra

E08 - O câncer, o que sabemos e 3,01 como podemos tratá-lo E05 - O que se pode fazer para 3,00 assegurar ar limpo e água potável E11-O que sabemos sobre HIV/Aids 2,99 e como controlá-la E42 - Fenômenos que os cientistas 2,99 ainda não conseguem explicar

\section{Meninas}

E10 - Como prestar primeiros 3,45 socorros

sabemos e como podemos tratá-lo

C13 - Por que sonhamos 3,34 e qual o significado dos nossos sonhos E09 - As doenças 3,33 sexualmente transmissiveis e como se proteger delas E11 - O que sabemos sobre 3,31 HIV/Aids e como controlá-la A40 - Como manter o 3,29 meu corpo forte e em boa condição física E13 - Como as diferentes 3,19 drogas proibidas podem afetar o nosso corpo A07 - Como o corpo humano 3,18 é feito e como funciona E07 - Como controlar 3,18 epidemias e doenças E23 - Como o meu corpo 3,17 cresce e se desenvolve A37 - 0 que comer para nos 3,14 mantermos saudáveis e em boa forma física 
E16 - Como proteger espécies de 2,98 animais ameaçados de extinção

A33 - O efeito dos choques elétricos 2,95 e dos relâmpagos no corpo humano

A37 - O que comer para nos 2,94 mantermos saudáveis e em boa forma física A48 - Como funciona uma usina 2,94 nuclear C13 - Por que sonhamos e qual o 2,93 significado dos nossos sonhos

A23 - Como meteoritos, cometas e 2,91 asteroides podem causar catástrofes na Terra

A27-Animais perigosos e venenosos 2,88

E21 - Novos recursos de energia - 2,88 sol, vento, marés, ondas, etc. E40 - Invenções e descobrimentos 2,87 que transformaram o mundo
E12 - Como o álcool e o 3,11 tabaco podem afetar o corpo humano

E05 - O que se pode fazer 3,10 para assegurar ar limpo e água potável

A26-Epidemias e doenças 3,07 que causam muitas mortes

C07-Como os computadores 3,07 funcionam

A09-Sexo e reprodução $\quad 3,05$

C08 - A possibilidade de vida 3,05 fora do planeta Terra

C11 - A vida, a morte e a alma 3,05 humana

E31 - Os aspectos biológicos 3,05 e humanos do aborto E32 - Como a tecnologia 3,05 genética pode evitar doenças

Fonte: Dados coletados pelos autores do artigo.

Podemos observar que dos 20 itens expostos acima, dentre os meninos, nove estão relacionados à Biologia Humana e, dentre as meninas, 17 estão relacionados a este tema. Ou seja, num grupo de 20 itens, $45 \%$ dos temas que mais interessam os jovens brasileiros na escola e $85 \%$ dos temas que mais interessam as jovens brasileiras na escola estão relacionados ao seu próprio corpo, tanto no que se refere aos seus cuidados como a questões polêmicas, como significado dos sonhos e alma humana (C11, C13).

Em seguida, os temas que os meninos apontaram como de maior interesse foram: Tecnologia (15\%), Meio Ambiente (15\%), Universo (10\%), Ciência, Tecnologia e Sociedade (10\%) e Zoologia (5\%). Dentre as meninas, os temas seguintes de maior interesse foram: Meio Ambiente (5\%), Tecnologia (5\%) e Universo/Mistério (5\%).

Osborne et al. (2003) identificaram, dentro da Biologia, a Biologia Humana como conteúdo relevante e pertinente do ponto de vista dos alunos, uma vez que está direcionado ao interesse do estudante pelo seu próprio corpo e a questões relacionadas a doenças e saúde. Os dados obtidos junto ao Rose no Brasil e em diversos países também caminham nessa direção. 
A pesquisa Rose realizada na Inglaterra apontou os dez temas que mais interessam os jovens ingleses: o tema Biologia Humana apareceu uma vez (10\%) na lista dos meninos e nove vezes (90\%) na lista das meninas (JENKINS; NELSON, 2005; JENKINS; PELL, 2006). Na Suécia, na lista dos itens mais populares entre os estudantes, $55 \%$ estão relacionados a temas da Biologia Humana (JIDESJÖ; OSCARSSON; KARLSSON, 2009). Na Finlândia, Irlanda, Itália, Estônia, Dinamarca e Israel também se observou grande interesse pelos temas da Biologia Humana, especialmente dentre as meninas (LAVONEN et al., 2005; MATTHEWS, 2007; NERESINI; CROVATO; SARACINO, 2010; TEPPO; RANNIKMÄE, 2004; TRUMPER, 2006). Também se verificou grande interesse pela Biologia Humana entre os jovens de Gana, porém de forma inversa: na lista dos temas de mais interesse dos meninos, $50 \%$ eram voltados para Biologia Humana, contra 40\% da lista das meninas (ANDERSON, 2006).

Os dados obtidos na presente pesquisa evidenciam que o jovem tem grande interesse pelo seu corpo, como ele funciona, as doenças que o afetam e, é claro, o sexo. 0 currículo de Ciências não pode passar ao largo deste fato para se tornar significativo para o aluno. 0 engajamento dos alunos pela ciência e pelas aulas de Ciências poderá ser impulsionado por estratégias que abordem tais temas, de forma que o interesse já existente, que é intrínseco ao jovem, poderá favorecer o despertar de interesse pelos demais conteúdos abordados na escola.

Os tópicos menos populares dentre os jovens brasileiros podem ser observados na Tabela 2.

Tabela 2 - Itens das seções A, C, e E do questionário Rose com menor pontuação entre os jovens brasileiros.

\section{Meninos}

E01 - Simetrias e padrões em folhas e flores

A10 - Controle de natalidade e contracepção

A41_- Cirurgias plásticas e

tratamentos de beleza

E37 - Cientistas famosos e as suas vidas

\section{Meninas}

E01 - Simetrias e padrões em

1,75

folhas e flores

E37 - Cientistas famosos e

as suas vidas 2,01

E26 - Os detergentes e

sabões e como funcionam

E28 - Como utilizar e

2,07 consertar equipamentos 2,09

elétricos e mecânicos 
E26 - Os detergentes e sabões e como funcionam

C14 - Bruxas e fantasmas, e se existem ou não

A17 - Átomos e moléculas

A39 - A capacidade de loções e cremes manterem a pele jovem A38 - As perturbaçoes alimentares, como anorexia e bulimia A08-Hereditariedadeecomo osgenes afetam o nosso desenvolvimento A42 - Como a luz solar e a dos bronzeadores artificiais afetam a 2,20 pele

C12 - Medicinas alternativas

(acupuntura, homeopatia, ioga, etc.) 2,21 e a sua eficácia

A15 - Como as plantas crescem e se reproduzem C18 - As propriedades das pedras e dos cristais e como são usados para 2,25 embelezar

A05 - Nuvens, chuva e tempo

2,25

C09 - Astrologia e horóscopos e se os planetas podem influenciar os seres 2,26 humanos

A11 - Como os bebês crescem e se desenvolvem E19 - A agricultura orgânica, sem uso de pesticidas e adubos artificiais E33 - Os benefícios e os possíveis perigos dos métodos modernos da agricultura E17 - Como se melhoram as colheitas em hortas e roças

A45 - O uso de satélites

para comunicação e outros 2,34 propósitos

A04 - Como evoluem e se transformam as montanhas, 2,37 rios e oceanos

2,29 A03 - O interior da Terra

A05 - Nuvens, chuva e tempo

E24 - Os animais da minha região

E27 - Eletricidade, sua

2,35 produção e uso doméstico

Fonte: Dados coletados pelos autores do artigo.

Ao observarmos a lista dos itens pelos quais os meninos brasileiros menos se interessam, verificamos, paradoxalmente, que oito dentre os 20 tópicos (40\%) referem-se à Biologia Humana. Dentre estes, cinco são relacionados 
a cuidados com o corpo e estética (A41, A39, A38, A42 e C12), temas tradicionalmente pertencentes ao universo feminino. Porém, três desses temas são relacionados à sexualidade (A10), hereditariedade (A08) e à vida cotidiana (A11). Os outros temas que menos interessam aos meninos são Botânica (20\%), Química (10\%) e Geociências (10\%).

O tema que as meninas brasileiras menos se interessam em aprender é Botânica (25\%), seguido por Química (15\%), Geociências (15\%) e assuntos ligados à Ciência, Tecnologia e Sociedade (15\%). É interessante verificar que havia na lista das meninas um único tema relacionado à Biologia Humana, também presente na lista dos meninos: Controle da natalidade e contracepção (A10). Assim, daremos destaque a esta questão em particular.

Diversos estudos no contexto brasileiro mostram problemas relacionados ao uso de contraceptivos entre os jovens, principalmente do sexo masculino. Antunes et al. (2002, p. 89) consideram que "as normas culturais presentes na socialização de meninos e meninas para a vida sexual continuam colocando homens e mulheres em situações vulneráveis”, uma vez que o conhecimento sobre métodos contraceptivos não implica mudanças de atitudes e práticas (BORGES; SCHOR, 2005).

Villela e Doreto (2006, p. 2471) apontam que "são múltiplos os caminhos que levam um jovem a ter relações sexuais desprotegidas, e os números que vêm à tona sobre a gravidez, DST ou [...] HIV sem dúvida são menores do que os números reais".

Diante de tais problemas, Tonatto e Sapiro (2002, p. 164) apontam que 0 ensino de Ciências em especial deve "oferecer à instituição escolar formas significativamente contextualizadas de se trabalhar as questões acerca da sexualidade", privilegiando os interesses e as necessidades dos estudantes. Para as autoras, o currículo deve atender às necessidades dos alunos, de forma a favorecer a compreensão da sociedade em que vivem.

Os dados obtidos nesta pesquisa apontam que o sexo desperta o interesse e a curiosidade dos jovens, porém é necessário que a escola estimule o interesse e atitudes positivas em relação aos métodos contraceptivos, tendo em vista os problemas envolvidos acerca da vulnerabilidade ${ }^{2}$ sexual dos jovens. Os dados revelam que a atual abordagem envolvendo controle da natalidade

\footnotetext{
A vulnerabilidade foi definida por Ayres (2003, p. 122) como "o movimento de considerar a chance de exposição das pessoas ao adoecimento como resultante de um conjunto de aspectos, não apenas individuais, mas coletivos, contextuais, que acarretam maior suscetibilidade à infecção e ao adoecimento".
} 
e contracepção não desperta o interesse dos nossos jovens, ao contrário, tem levado essa questão ao topo da lista dos temas indesejados. Cabe aos educadores repensarem a maneira como essa questão é tratada na escola, a fim de que a educação sexual ofereça, de fato, elementos que permitam aos jovens uma vida sexual saudável.

Assim, concordamos com as considerações de Jenkins (2006, p. 4), quando afirmou que "ouvir o estudante" é uma maneira de transformar a escolaridade, uma vez que "torna o currículo mais relevante para as necessidades e interesses dos alunos". Segundo o autor, conhecer os temas que interessam os alunos e considerá-los nas práticas educativas pode aumentar sua motivação e contribuir para melhorias no processo de ensino-aprendizagem.

\section{A evolução biológica e os jovens brasileiros}

A evolução tem sido considerada a pedra angular da Biologia. Segundo Colby (1996, p. 1), a pesquisa nessa área pode ser feita com escasso ou nenhum conhecimento da biologia evolutiva, mas, sem essa perspectiva, torna-se um conjunto de campos díspares. As explicações evolutivas transpassam todos os campos da Biologia, "unindo todas as áreas da biologia sob o mesmo guarda-chuva teórico".

A perspectiva evolutiva estabelece um horizonte imprescindivel para organizar e interpretar observações e fazer previsões em todas as áreas das Ciências Biológicas (FUTUYMA, 2002). Assim, a evolução biológica é considerada o eixo fulcral das Ciências Biológicas, sendo entendida como fator indispensável para uma boa compreensão dos conhecimentos biológicos.

No Brasil, os documentos oficiais salientam a relevância e, em alguns casos, recomendam expressamente que a evolução biológica seja um conceito unificador das Ciências Biológicas na educação básica por meio dos Parâmetros Curriculares do Ensino Médio (PCNEM), PCN+ e das Orientações Curriculares para o Ensino Médio (Ocem), e no nível superior por meio das Diretrizes Curriculares Nacionais (DCN) para os cursos de Ciências Biológicas.

Nos PCNEM, a evolução biológica como eixo integrador é destacada no estudo dos conteúdos que envolvem interações entre seres vivos, incluindo o ser humano, e demais elementos do ambiente, que podem "ensejar a questão da origem e da diversidade, até que o conhecimento da célula se apresente dentro da questão, como problema a ser desvendado para uma maior e melhor compreensão do fenômeno vida" (BRASIL, 2000, p. 16). 
Desse modo, percebe-se que o devido destaque ao ensino de evolução biológica como eixo central dos conhecimentos biológicos é abordado pelos documentos oficiais que imprimem as orientações curriculares no Brasil. Contudo, pesquisas realizadas no País (TIDON, LEWONTIN, 2004; BELLINI, 2006; OLIVEIRA, 2009) relatam intensas dificuldades no processo de ensino e aprendizagem de evolução, apontando que existem muitos obstáculos a serem transpostos para que o papel centralizador da evolução biológica seja colocado em prática nos currículos de Biologia.

A seção relativa à evolução biológica do questionário Rose aplicado no Brasil é composta por itens que abarcam uma perspectiva geral dos mecanismos evolutivos. As atitudes dos estudantes em relação à aceitação das questões que apresentam mecanismos evolutivos da ancestralidade comum e seleção natural (M3 - As espécies atuais de animais e plantas se originaram de outras espécies do passado e M10 - Diferentes espécies atuais podem ter um ancestral comum) estão dispostas na Tabela 3.

Tabela 3 - Frequência e porcentagens das questões que apresentam mecanismos evolutivos da ancestralidade comum e seleção natural.

\begin{tabular}{llll} 
Questão & Resposta & Frequência & Porcentagem \\
& & & (\%) \\
M3 - As espécies & Discordo totalmente & 259 & 11,0 \\
atuais de animais & Discordo & 372 & 15,7 \\
e plantas se & Concordo & 555 & 23,5 \\
originaram de & Concordototalmente & 956 & 40,4 \\
outras espécies do & Sem resposta & 223 & 9,4 \\
passado & Total & 2.365 & 100,0 \\
M10 - Diferentes & Discordo totalmente & 378 & 16,0 \\
espécies podem & Concordo & 545 & 23,0 \\
possuir uma mesma & Concordototalmente & 597 & 23,1 \\
espécie ancestral & Sem resposta & 299 & 25,2 \\
& Total & 2.365 & 12,6 \\
\hline
\end{tabular}

Fonte: Dados coletados pelos autores do artigo.

Os dados demonstram a aceitação de 1.511 jovens $(63,9 \%)$ nas questões que versam sobre o fato de as atuais espécies de animais e plantas se originarem de outras espécies do passado (M3). Já em relação ao item M10, que versa sobre diferentes espécies possuírem uma mesma espécie ancestral, os estudantes 
parecem bastante divididos: 923 discordam (39\%); 1.143 concordam (48,3\%) e 299 não responderam (12,6\%). Esses resultados revelam que os jovens estudantes participantes do estudo aceitam indícios de mecanismos da seleção natural, mas têm dúvidas em relação à ancestralidade comum.

A esse respeito, Goedert (2004) apontou que os professores sentem dificuldades ao ensinar o tema. Um dos entraves seria a não compreensão dos estudantes sobre os processos evolutivos quando trabalhados em sala de aula; geralmente, eles associam o significado do conceito "ancestral comum" com a expressão "veio do macaco".

Considerando que muitos professores, intimidados com as controvérsias envolvidas na abordagem da evolução biológica e com as suas próprias dificuldades de compreender as teorias evolutivas, furtam-se de trabalhála, indicamos nas propostas curriculares que se discuta a possibilidade real de inserir tal tema nas aulas de Biologia, uma vez que os próprios jovens brasileiros estão abertos aos estudos do assunto.

\section{CONSIDERAÇÕES FINAIS}

Esta pesquisa verificou que o assunto que mais desperta o interesse do jovem brasileiro na ciência escolar é a Biologia Humana, considerando as preferências de meninos e meninas. Questões relacionadas à sexualidade, cuidados com o corpo, doenças, os alimentos que ingerimos, etc., despertam a curiosidade dos nossos jovens. Os materiais didáticos e o próprio currículo de Ciências não podem se esquivar desse fato e continuar repetindo um modelo de abordagem de conteúdos que valorize pouco tais assuntos.

O engajamento dos alunos pela ciência e pelas aulas de Ciências poderá ser impulsionado por estratégias que abordem tais temas, de forma que o interesse já existente, que é intrínseco ao jovem, poderá favorecer o despertar do interesse pelos demais conteúdos abordados na escola.

Em contrapartida, um tema que interessa pouco, tanto meninos quanto meninas, é o Controle de natalidade e contracepção. Os dados apontam para a necessidade de a escola estimular o interesse e atitudes positivas em relação aos métodos contraceptivos, tendo em vista os vários problemas existentes acerca da vulnerabilidade sexual dos jovens.

Assim, devemos considerar o comentário de Aikenhead (2004, p. 6), que considera que "a educação científica tradicional tem desempenhado um 
papel insignificante na vida da maioria dos alunos”. A ciência escolar só irá envolver os alunos quando o currículo tiver valor pessoal para os estudantes.

Recomendamos que os currículos e os materiais didáticos levem em consideração a opinião daqueles que irão cursá-lo, dando destaque aos seus temas de interesse, privilegiando assuntos contextualizados em sua realidade e, principalmente, organizando-se de tal forma que os temas que já despertam o interesse, como a saúde, estejam vinculados aos assuntos pelos quais os jovens não demonstram tanto interesse, como os tópicos de química.

Em relação à evolução biológica, o fato de os alunos concordarem com os mecanismos da seleção natural revela que os estudantes brasileiros estão abertos a discussões acerca do tema em sala de aula. Por isso, se faz imperativo assegurar a abordagem da evolução biológica nos currículos de Biologia, de forma que se estabeleçam através da discussão do tema os alicerces desta ciência durante a educação básica. 


\section{Science curriculum and Brazilian students' interest: a necessary approach}

Abstract: Students' disillusion with scientific career has stirred up a movement aiming at listening to what they have to say about Science classes end major science subjects. One of these movements is "The Relevance of Science Education" project (Rose), implemented in more than 40 countries and subject of study of the work we describe here. Research is within the educational evaluation field. The national representativity sample involved 2.365 students from 84 different schools. Resulting data show that Brazilians have great interest in science-based subjects, especially those related to Human Biology. Particularly on biological evolution, a very controversial topic in the Biology curriculum, we can see that young Brazilian students are open for a discussion on it.

Key words: Science curriculum. Students' interest. Educational evaluation. 


\section{REFERÊNCIAS}

AIKENHEAD, Glen. The humanistic and cultural aspects of science \& technology education. In: XI IOSTE (INTERNATIONAL ORGANIZATION FOR SCIENCE AND TECHNOLOGY EDUCATION) SYMPOSIUM: SCIENCE AND TECHNOLOGY EDUCATION FOR A DIVERSE WORLD. Anais... Lublin: IOSTE, 2004.

ANDERSON, Ishmael Kwesi. The relevance of science education as seen by pupils in Ghanaian junior secondary schools. 2006. 376p. Tese (Doctor of Philosophy) - Department of Mathematics and Science Education, University os the Western Cape, Western Cape, 2006.

ANTUNES, Maria Cristina; PERES, Camila Alves; PAIVA, Vera; STALL, Ron; HEARST, Norman. Diferenças na prevenção da Aids entre homens e mulheres jovens de escolas públicas em São Paulo, SP. Revista de Saúde Pública, v. 36, n. 4, Supl., p. 88-95, 2002.

AYRES, José Ricardo Carvalho Mesquita; FRANÇA JUNIOR, Ivan; CALAZANS, Gabriela Junqueira; SALETTI FILHO, Heraldo César. O conceito de vulnerabilidade e as práticas de saúde: novas perspectivas e desafios. In: CZERESNIA, D.; FREITAS, C. M. DE. (Eds.). Promoção da saúde: conceitos, reflexões, tendências. Rio de Janeiro: Fiocruz, 2003, p. 117-139.

BARAM-TSABARI, Ayelet; SETHI, Ricky; BRY, Lynn; YARDEN, Anat. Asking scientists: A decade of questions analyzed by age, gender, and country. Science Education, v. 93, n. 1, p. 131-160, jan. 2009.

; YARDEN, Anat. Characterizing children's spontaneous interests in science and technology. International Journal of Science Education, v. 27, n. 7, p. 803-826, jan. 2005.

BELLINI, Luiza Marta. Avaliação do conceito de evolução nos livros didáticos. Estudos em Avaliação Educacional, v. 17, n. 33, p. 7-28, 2006.

BORGES, Ana Luiza Vilela; SCHOR, Néia. Início da vida sexual na adolescência e relações de gênero: um estudo transversal em São Paulo, Brasil, 2002. Cadernos de Saúde Pública, v. 21, n. 2, p. 499-507, 2005.

BRASIL. Parâmetros Curriculares Nacionais: Ensino Médio. Secretaria de Educação Média e Tecnológica, Brasília: MEC, 2000.

BURIASCO, Regina Luzia Corio de. Algumas considerações sobre avaliação educacional. Estudos em Avaliação Educacional, v. 22, p. 155-178, 2000. 
CAVAS, Bulent; CAVAS, PInar; TEKKAYA, Ceren; CAKIROGLU, Jale; KESERCIOGLU, Teoman. Turkish Students' Views on environmental challenges with respect to Gender: An analysis of ROSE data. Science Education International, v. 20, n. 1/2, p. 69-78, 2009.

CHASSOT, Attico. Alfabetização científica: questões e desafios para a educação. 4. ed. ljuí: Ed. Unijuí, 2006. 440 p.

COLBY, Chris. Introduction to evolutionary biology. The Talk Origins Archive, 7 jan. 1996. Disponível em: 〈http://www.talkorigins.org/faqs/faq-intro-tobiology.html>. Acesso em: 10 dez. 2012.

DEBOER, George. Scientific literacy: Another look at its historical and contemporary meanings and its relationship to science education reform. Journal of Research in Science Education, v. 37, n. 6, p. 582-601, 2000.

EUROPEAN COMMISSION. Europe needs more scientists! Report by the High Level Group on Increasing Human Resources for Science and Technology in Europe. Luxembourg: Office for Official Publications of the European Communities, 2004. 187 p.

Science education now: A renewed pedagogy for the future of Europe. Luxembourg: Office for Official Publications of the European Communities, 2007. 22 p.

FENSHAM, Peter. Increasing the relevance of science and technology education for all students in the 21st Century. Science Education International, v. 15, n. 1, p. 7-26, 2004.

FOUREZ, Gérard. Crise no ensino de ciências? Investigações em Ensino de Ciências, v. 8, n. 2, p. 109-123, 2003.

FUTUYMA, Douglas. Evolução, ciência e sociedade. São Paulo: Sociedade Brasileira de Genética, 2002.

GATTI, Bernadette. Estudos quantitativos em educação. Educação e Pesquisa, v. 30, n. 1, p. 11-30, abr. 2004.

GOEDERT, Lidiane. A formação do professor de biologia na UFSC e o ensino da evolução biológica. 2004. 126f. Dissertação (Mestrado em Educação Científica e Tecnológica). Faculdade de Educação, Universidade Federal de Santa Catarina, Florianópolis, 2004. 
JENKINS, Edgard. The student voice and school science education. Studies in Science Education, v. 42, n. 1, p. 49-88, 2006.

; NELSON, N. W. Important but not for me: students' attitudes towards secondary school science in England. Research in Science \& Technological Education, v. 23, n. 1, p. 41-57, 2005.

; PELL, R. G. The relevance of science education project (ROSE) in England: A summary of findings. Leeds: Centre for Studies in Science and Mathematics Education, 2006. 84 p.

JIDESJÖ, Anders; OSCARSSON, Magnus; KARLSSON, Karl-Göran. Science for all or science for some: What Swedish students want to learn about in secondary science and technology and their opinions on science lessons. NorDiNa, v. 5, n. 2, p. 213-229, 2009.

KWIEK, Nicole et al. Pharmacology in the High-School Classroom. Science, v. 317, p. 1871-1872, 2007.

LAVONEN, Jari; JUUTI, Kalle; UITTO, Anna; MEISALO, Veijo; BYMAN, Reijo. Attractiveness of science education in the Finnish comprehensive school. In: MANNINEN, A.; MIETTINEN, K.; KIVINIEMI, K. (Eds.). Research findings on young people's perceptions of technology and science education: Mirror results and good practice. Hensinki: Technology Industries of Finland, 2005, p. 2-43.

MATTHEWS, Phillip. The relevance of science education in Ireland. Dublin: Royal Irish Academy, 2007. 106 p.

NERESINI, Federico; CROVATO, Stefania; SARACINO, Barbara. Scienza e nuove generazioni: I risultati dell'indagine internazionale ROSE. Vicenza: Edizioni Observa Science in Society, 2010. 189 p.

OECD. Evolution of student interest in science and technology studies: Policy report. Global Science Forum: OECD, 2006. 18 p.

OEl 2021 - Metas educativas. La educación que queremos para la generación de los bicentenários. Madrid: OEl-Cepal-Secretaría General Iberoamericana, 2010.

OLIVEIRA, Graciela da Silva. Aceitação/rejeição da evolução biológica: atitudes de alunos da educação básica. 2009. 162f. Dissertação (Mestrado em Educação) - Faculdade de Educação, Universidade de São Paulo, São 
Paulo, 2009.

OSBORNE, Jonathan. Message from the president. E-NARST News, v. 49, n. 2, p. 1-2, 2006.

; DILLON, Justin. Science education in Europe: Critical reflections. A report to the Nuffield Foundation. London: The Nuffield Foundation, 2008. 32 p.

; SIMON, Shirley; COLLINS, Sue. Attitudes towards science: a review of the literature and its implications. International Journal of Science Education, v. 25, n. 9, p. 1049-1079, set. 2003.

POLINO, Carmelo; CHIAPPE, Dolores. Introducción: los jóvenes, nas carreras científicas y los dilemas de la educación media. In: POLINO, Carmelo (org.). Los estudiantes y la ciencia: Encuesta a jóvenes iberoamericanos. Buenos Aires: Organización de Estados Iberoamericanos para la Educación, la Ciencia y la Cultura, 2011. 286 p.

SCHREINER, Camilla; SJØBERG, Svein. Sowing the seeds of ROSE. Acta Didactica 4/2004, p. 120, 2004.

SHAMOS, Morris; HOWES, Ruth. The myth of scientific literacy. Physics Today, v. 49, n. 3, p. 89, 1996.

SJØBERG, Svein. Science and scientists: The SAS-study. Acta Didactica 1/2000, v. 1, p. 75, 2000.

TEPPO, Moonika; RANNIKMÄE, Miia. Relevant science education in the eyes of grade nine students. In: XI INTERNATIONAL ORGANIZATION FOR SCIENCE AND TECHNOLOGY EDUCATION (IOSTE) SYMPOSIUM: SCIENCE AND TECHNOLOGY EDUCATION FOR A DIVERSE WORLD. Anais...Lublin: IOSTE, 2004.

TIDON, Rosana, LEWONTIN, Richard Charles. Teaching evolutionary biology. Genetics and Molecular Biology, v. 27, n. 1, p. 124-131, 2004.

TOLENTINO NETO, Luiz Caldeira Brant de. Os interesses e posturas de jovens alunos frente às ciências: resultados do Projeto ROSE aplicado no Brasil. 2008. 172f. Tese (Doutorado em Educação) - Faculdade de Educação, Universidade de São Paulo, São Paulo, 2008.

TOMEI, Anthony. Foreword. In: OSBORNE, J.; DILLON, J. (Eds.). Science education in Europe: Critical reflections. A report to the Nuffield Foundation. 
London: The Nuffield Foundation, 2008, p. 5-5.

TONATTO, Suzinara; SAPIRO, Clary Milnitsky. Os novos parâmetros curriculares das escolas brasileiras e educação sexual: uma proposta de intervenção em ciências. Psicologia \& Sociedade, v. 14, n. 2, p. 163-175, 2002.

TRUMPER, Ricardo. Factors affecting Junior High School students' interest in biology. Science Education International, v. 17, n. 1, p. 31-48, 2006.

VÁZQUEZ ALONSO, Ángel; MANASSERO MAS, Maria Antonia. El declive de las actitudes hacia la ciencia de los estudiantes: un indicador inquietante para la educación científica. Rev. Eureka Enseñ. Divul. Cien., v. 5, n. 3, p. 274-292, 2008.

VIANNA, Heraldo Marelim. Avaliação educacional nos Cadernos de Pesquisa. Estudos em Avaliação Educacional, n. 80, p. 100-105, 1992.

VILLELA, Wilza Vieira; DORETO, Daniella Tech. Sobre a experiência sexual dos jovens. Cadernos de Saúde Pública, v. 22, n. 11, p. 2467-2472, 2006.

RECEBIDO: Junho de 2014.

APROVADO: Agosto de 2014. 
Anexo 1: Afirmações presentes nas seções A, C e E do Questionário Rose aplicado no Brasil

Seções A, C e E: O que eu quero aprender. Qual é o seu nivel de interesse em aprender os seguintes assuntos ou temas? Opções de resposta: Desinteressado a muito interessado.

A01 - Estrelas, planetas e o Universo

A02 - Substâncias quimicas, suas propriedades e como reagem

A03 - O interior da Terra

A04 - Como evoluem e se transformam as montanhas, rios e oceanos

A05 - Nuvens, chuva e tempo

A06 - Origem e evolução da vida na Terra

A07 - Como o corpo humano é feito e como funciona

A08 - Hereditariedade e como os genes afetam o nosso desenvolvimento

A09 - Sexo e reprodução

A 10 - Controle de natalidade e contracepção

A11 - Como os bebês crescem e se desenvolvem

A12 - Clonagem de animais

A13 - Animais de diversas partes do mundo

A14 - Dinossauros, como viveram e por que desapareceram

A 15 - Como as plantas crescem e se reproduzem

A16 - Como as pessoas, animais, plantas e ambiente dependem uns dos outros

A17 - Átomos e moléculas

A18 - Como a radioatividade afeta o corpo humano

A19 - A luz invisivel à nossa volta (infravermelho, ultravioleta)

A20 - Como os animais utilizam cores para se esconderem, atrairem ou assustarem

A21 - Como diferentes instrumentos musicais produzem sons diferentes

A22 - Buracos negros, supernovas e outros objetos do espaço

A23 - Como meteoritos, cometas e asteroides podem causar catástrofes na Terra

A24 - Terremotos e vulcões

A25 - Tornados, furacồes e ciclones
A26 - Epidemias e doenças que causam muitas mortes

A27 - Animais perigosos e venenosos

A28 - Plantas tóxicas da minha região

A29 - Venenos mortais e o que estes fazem ao corpo humano

A30 - Como funciona a bomba atômica

A31 - Quimicos explosivos

A32 - Armas biológicas e químicas e o que fazem ao corpo humano

A33 - O efeito dos choques elétricos e dos relâmpagos no corpo humano

A34 - Qual a sensação de viver sem peso no espaço

A35 - Como caminhar orientado pelas estrelas

A36 - Como o olho consegue ver luz e cores

A37 - O que comer para nos mantermos

saudáveis e em boa forma fisica

A38 - As perturbações alimentares, como anorexia e bulimia

A39 - A capacidade de loções e cremes manterem a pele jovem

A40 - Como manter o meu corpo forte e em boa condição fisica

A41 - Cirurgias plásticas e tratamentos de beleza A42 - Como a luz solar e a dos bronzeadores artificiais afetam a pele

A43 - Como nosso organismo consegue ouvir diferentes sons

A44 - Foguetes, satélites e viagens espaciais A45 - O uso de satélites para comunicação e outros propósitos

A46 - Como o raio $\mathrm{x}$, o ultrassom, etc. são usados na medicina

A47 - Como funcionam os motores a diesel, a álcool, a gás e a gasolina

A48 - Como funciona uma usina nuclear 
Seções A, C e E: O que eu quero aprender. Qual é o seu nivel de interesse em aprender os seguintes assuntos ou temas? Opções de resposta: Desinteressado a muito interessado.

C01 - Como o petróleo é transformado em outros materiais como plásticos e tecidos

$\mathrm{C} 02$ - Instrumentos ópticos e como funcionam (telescópio, máquina fotográfica, microscópio, etc.)

$\mathrm{C} 03$ - O uso do raio laser para efeitos técnicos (gravadores de CDs, leitores de códigos de barra, etc.)

C04 - Como fitas cassete, gravadores de CD e DVD armazenam e reproduzem sons e música

C05 - Como funcionam coisas como o rádio e a televisão

C06 - Como os telefones celulares enviam e recebem mensagens

C07 - Como os computadores funcionam

C08 - A possibilidade de vida fora do planeta Terra

C09 - Astrologia e horóscopos e se os planetas podem influenciar os seres humanos

C10 - Os mistérios do espaço ainda por resolver

C11 - A vida, a morte e a alma humana

C12 - Medicinas alternativas (acupuntura, homeopatia, ioga, etc.) e a sua eficácia

$\mathrm{C} 13$ - Por que sonhamos e qual o significado dos nossos sonhos

C14 - Bruxas e fantasmas, e se existem ou não.

C15 - Transmissão de pensamentos, leitura de mentes, sexto sentido, intuição, etc.

$\mathrm{C} 16$ - Por que as estrelas brilham e porque o céu é azul

C17 - Por que conseguimos ver o arco-íris

C18 - As propriedades das pedras e dos cristais e como são usados para embelezar

E01 - Simetrias e padrões em folhas e flores

E02 - Como se formam no céu as cores do pôr do sol
E03 - A camada de ozônio e como pode ser afetada pelos seres humanos

E04 - O efeito estufa e como pode ser modificado pelos seres humanos

E05 - O que se pode fazer para assegurar ar limpo e água potável

E06 - Como a tecnologia nos ajuda a tratar de residuos, lixo e esgotos

E07 - Como controlar epidemias e doenças

E08 - $\mathrm{O}$ câncer, o que sabemos e como podemos tratá-lo

E09 - As doenças sexualmente transmissiveis e como se proteger delas

E10 - Como prestar primeiros socorros

E11 - O que sabemos sobre HIV/AIDS e como controlá-la

E12 - Como o álcool e o tabaco podem afetar o corpo humano

E13 - Como as diferentes drogas proibidas podem afetar o nosso corpo

E14 - Os possiveis perigos de radiações de telefones celulares e computadores

E15 - Como os sons e ruidos altos podem prejudicar a minha audição

E16 - Como proteger espécies de animais ameaçados de extinção

E17 - Como se melhoram as colheitas em hortas e roças

E18 - Uso medicinal de plantas

E19 - A agricultura orgânica, sem uso de pesticidas e adubos artificiais

E20 - Como a energia pode ser poupada e usada de forma mais eficaz

E21 - Novos recursos de energia - sol, vento, marés, ondas, etc.

E22 - Como são produzidos, conservados e armazenados os diferentes tipos de alimentos 
Seções A, C e E: O que eu quero aprender. Qual é o seu nivel de interesse em aprender os seguintes assuntos ou temas? Opções de resposta: Desinteressado a muito interessado.

E23 - Como o meu corpo cresce e se desenvolve

E24 - Os animais da minha região

E25 - As plantas da minha região

E26 - Os detergentes e sabões e como funcionam

E27 - Eletricidade, sua produção e uso doméstico

E28 - Como utilizar e consertar equipamentos elétricos e mecânicos

E29 - A primeira viagem para a lua e a história da exploração do espaço

E30 - Como a eletricidade influenciou o desenvolvimento da nossa sociedade

E31 - Os aspectos biológicos e humanos do aborto

E32 - Como a tecnologia genética pode evitar doenças

E33 - Os beneficios e os possiveis perigos dos métodos modernos da agricultura

Seção I - Qual é a sua religião? Opções de resposta: Católica, Evangélica, Outras denominações protestantes, Budista, Judaica, Islâmica, Candomblé, Umbanda, Espírita Kardecista, Nenhuma, Outras. Se outra, qual?

Seção J - Quanto pratico minha religião. Quantas vezes frequento o serviço religioso? Opções de resposta: nunca a muitas vezes.

J01 - Compareço a igreja, templo ou a outros serviços religiosos

J02 - Frequento a igreja por influência familiar

Seção L - O que eu concordo. Qual é o seu nível de aceitação das seguintes afirmações? Opções de resposta: Não concordo a concordo.

L01 - Sou uma pessoa religiosa, ou uma pessoa de fé

L02 - Compreendo e acredito na doutrina ou nos ensinos religiosos.

L03 - Participo com frequência das reuniōes da minha religião.

L04 - Minha religião me impede de acreditar na evolução biológica.

L05 - Minha fé e/ou moral afetariam minha escolha de alguma carreira.

L06 - Sinto que minha fé contradiz as teorias cientificas atuais. 
Seção M - O que eu concordo. Qual é o seu nível de aceitação das seguintes afirmações? Opções de resposta: Não concordo a concordo.

M01 - A formação do planeta Terra se deu há cerca de 4,5 bilhôes de anos.

M02 - Os fósseis são indícios de espécies que viveram no passado.

M03 - As espécies atuais de animais e plantas se originaram de outras espécies do passado.

M04 - Os individuos que têm muitos descendentes transmitem suas caracteristicas vantajosas às novas geraçōes.

M05 - A formação de um fóssil pode demorar milhões de anos.

M06 - A evolução ocorre tanto em plantas como em animais.

M07 - Os humanos primitivos eram presas de dinossauros carnivoros.

Seção N - Você já estudou sobre os assuntos citados acima nas aulas de ciências? Opções de resposta: Não/ Sim, poucos/Sim, a maioria e Sim, todos.
M08 - Os primeiros seres humanos viveram no ambiente africano.

M09 - A espécie humana habita a Terra há cerca de 100.000 anos.

M10 - Diferentes espécies atuais podem ter um ancestral comum.

M11 - As condiçôes na Terra primitiva favoreceram a ocorrência de reações quimicas que transformavam compostos inorgânicos em compostos orgânicos que acabaram gerando vida

M12 - Os humanos primitivos eram caçadores de dinossauros herbivoros.

M13 - O ser humano se originou da mesma forma como as demais espécies biológicas. 